\title{
Associations between feed efficiency and aspects of lactation curves in primiparous Holstein dairy cattle
}

\author{
D. J. Seymour, ${ }^{1,2 *} \dagger \odot$ A. Cánovas, ${ }^{2} \odot$ T. C. S. Chud, ${ }^{2} \odot$ J. P. Cant, ${ }^{1} \odot$ V. R. Osborne, ${ }^{1} \odot$ C. F. Baes, ${ }^{2,3} \odot$ \\ F. S. Schenkel, ${ }^{2} \odot$ and F. Miglior ${ }^{2}(\odot)$ \\ ${ }^{1}$ Centre for Nutrition Modelling, Department of Animal Biosciences, University of Guelph, N1G 2W1, Guelph, Ontario, Canada \\ ${ }^{2}$ Centre for Genetic Improvement of Livestock, Department of Animal Biosciences, University of Guelph, N1G 2W1, Guelph, Ontario, Canada \\ ${ }^{3}$ Institute of Genetics, Vetsuisse Faculty, University of Bern, 3001, Bern, Switzerland
}

\section{ABSTRACT}

Genetic selection for improved feed efficiency in dairy cattle has received renewed attention over the last decade to address the needs of a growing global population. As milk yield is a critical component of feed efficiency metrics in dairy animals, our objective was to evaluate the associations between feed efficiency in primiparous Holstein cattle and parameters of a mathematical model describing individual lactation curves. The Dijkstra lactation curve model was fit to individual lactation records from 34 Holstein heifers with previously estimated measures of feed efficiency. We found that the optimal fit of the Dijkstra model was achieved using daily milk yield records up to $21 \mathrm{~d}$ in milk to capture the rise to peak milk yield and using monthly dairy herd improvement records for the remainder of lactation to accurately characterize lactation persistency. In the period of lactation before peak milk yield, improved feed efficiency was associated with a faster increase in daily milk yield over a shorter period of time at the expense of increased mobilization of body reserves; this serves to reinforce the concept that dairy cattle are primarily capital breeders versus income breeders. Feed efficiency in the period following peak lactation, as measured by gross feed efficiency, return over feed costs, and net energy efficiency of lactation, was positively associated with higher peak milk yield. The findings in early lactation suggest that estimates of feed efficiency could be improved by evaluating feed efficiency relative to conception, rather than parturition and lactation, to better account for the energy stored and released from body reserves in capital breeding.

Key words: capital breeding, mathematical model, persistency

Received December 8, 2020

Accepted March 29, 2021.

*Corresponding author: dave.seymour@trouwnutrition.com

$\dagger$ Current affiliation: Trouw Nutrition R\&D, PO Box 299, 3800 AG Amersfoort, the Netherlands.

\section{INTRODUCTION}

The continued growth of the global population necessitates the production of more food with finite natural resources. Ruminants, such as dairy cattle, are well positioned to fill this nutrient deficit through the ability to utilize cellulose as an energy source, allowing them to convert plant material into high-quality protein sources suited for inclusion in the human food chain, such as milk (Morgavi et al., 2010). These factors have stimulated a renewed interest in feed efficiency research in dairy cattle, with an emphasis on the potential for using selective breeding and advances in genetics to improve this trait (as reviewed by VandeHaar et al., 2016; Miglior et al., 2017; Brito et al., 2020).

A critical aspect of determining feed efficiency is the measurement of individual feed intake. Although this is a relatively straightforward process, it becomes more challenging as the number of animals increases; this results in rising costs due to either increased labor or investment in equipment to automate the process (Seymour et al., 2019). Due to the high cost, most methods of measuring individual intakes are not economically feasible in production settings. However, the majority of farms have milk record data on individual cows, whether they are daily records automatically recorded by milking systems or data collected at regular intervals by dairy herd improvement organizations. As milk yield forms a critical component of all metrics of feed efficiency in lactating dairy cattle, there is potential that feed efficiency may be closely related to aspects of the lactation curve, such as persistency (Capuco et al., 2003; Capuco and Ellis, 2013).

Various mathematical models can be used to describe lactation curves, such as those by Wood (1967), Wilmink (1987), Grossman and Koops (1988, 2003), Grossman et al. (1999), Pollott (2000), and Rook et al. (2009); however, the model proposed by Dijkstra et al. (1997) has biologically relevant parameters and has recently been shown to provide better fit than other models (Dematawewa et al., 2007; Pot, 2020). Using 
these models, it is theoretically possible to use milk yield data collected at regular intervals, such as monthly records collected as part of dairy herd improvement programs, and interpolate missing values based on the estimated lactation curve function. Considering this, the objectives of this study were to evaluate the relationship between daily estimates of feed efficiency and the parameters describing the lactation curves of primiparous Holstein cattle.

\section{MATERIALS AND METHODS}

\section{Data Collection and Feed Efficiency}

All animal procedures were approved by the Animal Care Committee at the University of Guelph (Animal Utilization Protocol No. 3503). Methods pertaining to data collection and estimation of feed efficiency were previously described in detail by Seymour et al. (2020). In brief, daily records for feed intake, milk and component yields, BW, and BCS were collected on 40 individual primiparous Holstein heifers housed at the Ontario Dairy Research Centre (Centre Wellington, ON, Canada) over the first 150 DIM. These data were then used to estimate several measures of feed efficiency on a daily basis: gross feed efficiency (GFE, $\mathrm{kg}$ of fat- and protein-corrected milk/kg of DMI), return over feed costs (ROFC, $\$ /$ d; the price of milk and component yields minus feed costs), residual feed intake ( $\mathrm{kg}$ of DM/d; Koch et al., 1963), residual net energy intake (REI, Mcal of $\mathrm{NE}_{\mathrm{L}} / \mathrm{d}$; Fischer et al., 2018), and the net energy efficiencies $\left(\% /\right.$ d) of lactation $\left(\mathbf{N E E}_{\mathbf{L}}\right)$, maintenance, and reserve energy (RE) flux $\left(\mathbf{N E E}_{\mathbf{F}}\right.$; Seymour et al., 2020). Mean net energy balance (NEBal; Mcal of $\mathrm{NE}_{\mathrm{L}} / \mathrm{d}$ ) was evaluated as the average across days, and the cumulative value was calculated as the sum across days within each animal. The cumulative values for gain in body RE (REGain), loss in body RE (RELoss), and flux of body RE were calculated as the sum of each value across days (Mcal of $\mathrm{NE}_{\mathrm{L}} / \mathrm{d}$ ) within each animal; REGain was estimated as the $\mathrm{NE}_{\mathrm{L}}$ flux from the pool of available net energy to the pool of body $\mathrm{RE}$, and RELoss was estimated as the $\mathrm{NE}_{\mathrm{L}}$ flux in the opposite direction. Details on the calculation of these fluxes and the RE pool were previously described in Seymour et al. (2020).

The model used to predict REI was revised from that originally described in Seymour et al. (2020) in an attempt to more accurately characterize changes in net energy sinks related to changes in BW, BCS, or both. The updated REI predictions were generated using the MIXED procedure of SAS version 9.4 (SAS Institute Inc.) according to the model

$$
\begin{gathered}
\text { NEI }_{i j}=\mu+\text { DIM }_{j}+b_{1} \text { NELact }_{i}+b_{2} \text { NEMaint }_{i} \\
+b_{3} \mathrm{RE}_{i}+b_{4} \text { REGain }_{i}+b_{5} \text { RELoss }_{i}+\mathrm{REI}_{i j},
\end{gathered}
$$

where $\mathrm{NEI}_{i j}$ is the observed $\mathrm{NE}_{\mathrm{L}}$ intake for animal $i$ on the $j$ th DIM (0 to 150), $\mu$ is the overall mean, $\mathrm{DIM}_{j}$ is the fixed effect of the $j$ th DIM, $b_{1}$ is the regression coefficient of $\mathrm{NE}_{\mathrm{L}}$ intake on milk $\mathrm{NE}_{\mathrm{L}}$ output (NELact) measured on the $j$ th DIM, $b_{2}$ is the regression coefficient of $\mathrm{NE}_{\mathrm{L}}$ intake on the estimated maintenance energy expenditures (NEMaint; $0.08 \times \mathrm{BW}^{0.75}$ ) on the $j$ th DIM, $b_{3}$ is the regression coefficient of $\mathrm{NE}_{\mathrm{L}}$ intake on the estimated body RE on the $j$ th DIM, $b_{4}$ is the regression coefficient of $\mathrm{NE}_{\mathrm{L}}$ intake on REGain on the $j$ th DIM, $b_{5}$ is the regression coefficient of $\mathrm{NE}_{\mathrm{L}}$ intake on RELoss on the $j$ th DIM, and $\mathrm{REI}_{i j}$ is the residual error term assumed to be independently and approximately normally distributed about a mean of zero with a variance of $\sigma_{e}^{2}$. All terms were in units of megacalories of $\mathrm{NE}_{\mathrm{L}}$ per day.

\section{Lactation Curve Modeling}

Individual lactation curves were modeled using the equation of Dijkstra et al. (1997):

$$
M=M_{0} \exp \left\{\frac{\mu_{T}\left[1-\exp \left(-k_{2} t\right)\right]}{k_{2}}-\lambda t\right\},
$$

where $M$ is the daily milk yield $(\mathrm{kg} / \mathrm{d})$ on day in milk $t, M_{0}$ is the theoretical milk yield $(\mathrm{kg} / \mathrm{d})$ at the onset of lactation $(t=0), \mu_{T}$ is the specific rate of secretory cell proliferation $\left(\mathrm{d}^{-1}\right)$ at parturition $(t=0), k_{2}$ is the specific rate of decay of cell proliferation $\left(\mathrm{d}^{-1}\right)$, and $\lambda$ is the specific rate of secretory cell apoptosis $\left(\mathrm{d}^{-1}\right)$.

Preliminary analyses were conducted to evaluate parameter estimation using either daily milk yield records spanning the first 150 DIM or monthly records spanning the entire lactation collected as part of the dairy herd improvement program. The model was initially fit to individual lactation curves within each data set, and the average model parameters from each data set were compared with the average daily milk yield over the first 150 DIM. When using average model parameters fit to exclusively daily records, the overall behavior (e.g., shape) of the resulting lactation curves was not representative of the observed daily milk yields, particularly the slope after peak milk yield (Figure 1, dotted line), suggesting bias in the estimation of $\lambda$. When using average model parameters fit to only monthly milk yield records spanning the full lactation, the resulting curves were more similar to daily records. However, a vertical 
shift was observed that resulted in the overestimation of all daily milk yields (Figure 1, solid line). This vertical shift was most likely due to the overestimation of $M_{0}$, as illustrated by the dashed line in Figure 1. Although the average of parameters from multiple lactation curves likely does not translate well to describing the average of the data used to generate the individual parameter estimates, these results suggested that records in early lactation were necessary for the accurate estimation of $M_{0}$, whereas records spanning the full lactation were necessary for the accurate estimation of $\lambda$. To address this, a combination of daily and monthly records was used to model the individual lactation curves for each animal.

All parameters were estimated using the NLIN procedure of SAS using the Marquardt estimation method with a maximum of 3,000 iterations and 300 subiterations. Milk yield observed on the first day of lactation was used as the initial value for $M_{0}$; in instances where no record was available for that day, the average initial milk yield was used. A range of initial values was used for the remaining parameters as follows: 0.01 to 0.10 by 0.01 for both $\mu_{T}$ and $k_{2}$, and 0.001 to 0.010 by 0.001 for $\lambda$ (Pot, 2020). These parameters were also constrained to be greater than zero.

To identify the optimal number of daily records to supplement, initial lactation curves were fit for all animals with available milk records that had completed their first lactation $(\mathrm{n}=138)$. Starting with monthly milk yield records spanning the entire lactation collected as part of the dairy herd improvement program, daily records from on-farm milking equipment were iteratively added to the data set until all daily milk records from the first 150 DIM were included. As part of the dairy herd improvement program, milk yield and samples for determination of milk composition were collected in 24-h windows, though these windows did not always fall within the same calendar day (i.e., samples collected at an evening milking and the following morning milking); as such, yields on a given date were subject to differ from those recorded by the onfarm equipment. In instances where daily and monthly milk records differed, the average of the 2 was used. Within each iteration, lactation curve parameters were first estimated using the combined daily and monthly records. These parameters were then used to fit the model to the full set of exclusively daily milk records by specifying the MAXITER $=0$ and PDATA options of the NLIN procedure.

Model fit was evaluated at each iteration by calculating the root mean square prediction error (RMSPE) using projected residuals (Cook and Tsai, 1985) and a bootstrap case resampling method adapted from Cassell (2007). In brief, projected residuals from the model

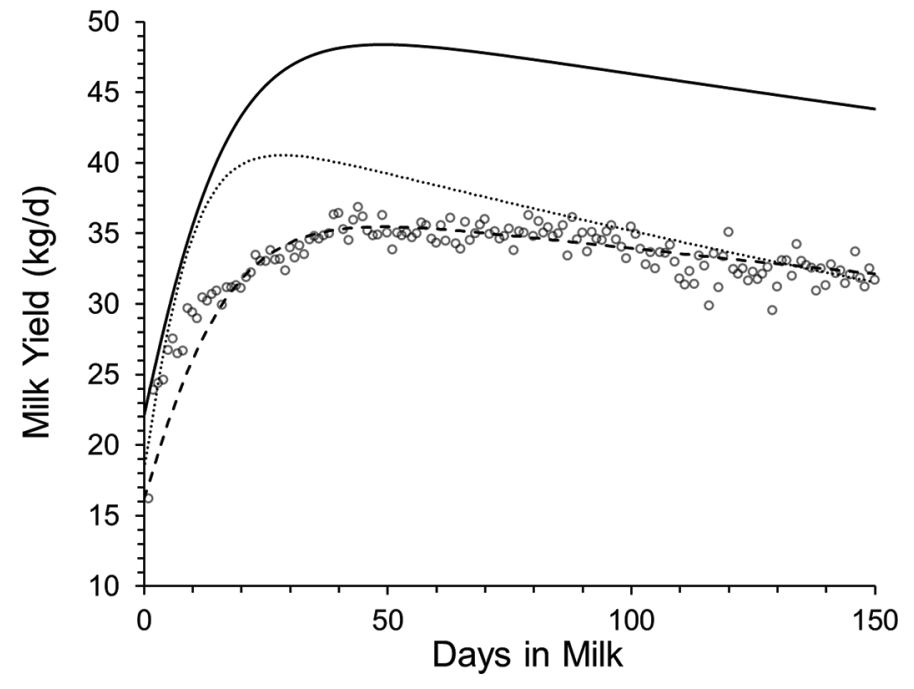

Figure 1. Preliminary analyses of parameterizations of lactation curves in primiparous Holstein cattle $(\mathrm{n}=138)$. Circles: average observed daily milk yield; solid line: lactation curve fit using average parameter estimates of models parameterized to monthly records spanning full lactation; dotted line: lactation curve fit using average parameter estimates of models parameterized to daily records up to 150 DIM; dashed line: lactation curve fit using average parameter estimates of models parameterized to monthly records spanning full lactation, with a manually adjusted value of the theoretical milk yield $(\mathrm{kg} / \mathrm{d})$ at the onset of lactation $\left(M_{0}\right)$.

were randomly selected using the unrestricted random sampling method of the SURVEYSELECT procedure of SAS and paired to the daily milk yields predicted by the same model. The predicted and projected residual milk yields were summed to generate pseudodata for each animal. The model was then refit to the pseudodata, and the resulting projected residuals were used to calculate the RMSPE. This was repeated a total of 100 times for each additional daily record supplemented to the monthly records, allowing for the calculation of average RMSPE for each daily milk yield record added to the data set. After identifying the optimal number of daily records to include, we considered only lactation curves from animals with accompanying feed efficiency data $(\mathrm{n}=40)$.

To evaluate the persistency of lactation on each day, the first derivative of the Dijkstra lactation curve function was derived using Maple version 1362973 (Waterloo Maple Inc.):

$M^{\prime}=M_{0}\left[\mu_{T} \exp \left(-k_{2} t\right)-\lambda\right] \exp \left\{\frac{\mu_{T}\left[1-\exp \left(-k_{2} t\right)\right]}{k_{2}}-\lambda t\right\}$,

where $M^{\prime}$ is the rate of change in daily milk yield (i.e., persistency, $\left.\mathrm{kg} / \mathrm{d}^{2}\right)$ on day in milk $t$. Model parameters were used to estimate peak milk yield $\left(\boldsymbol{M}_{\boldsymbol{P}}, \mathrm{kg} / \mathrm{d}\right)$, 


$$
M_{P}=M_{0}\left(\frac{\lambda}{\mu_{T}}\right)^{\frac{\lambda}{k_{2}}} \exp \left(\frac{\mu_{T}-\lambda}{k_{2}}\right),
$$

and time to peak milk yield $\left(\boldsymbol{t}_{\boldsymbol{P}}, \mathrm{d}\right)$,

$$
t_{P}=\frac{\ln \left(\frac{\mu_{T}}{\lambda}\right)}{k_{2}},
$$

as described by Dijkstra et al. (1997). The magnitude of change from initial to peak milk yield was calculated as the difference between $M_{P}$ and $M_{0}$. The estimated value for $t_{P}$ was used to generate 2 periods for each animal; data where DIM was less than or equal to $t_{P}$ were considered prepeak lactation, whereas data for DIM greater than $t_{P}$ were considered postpeak lactation.

\section{Model Evaluation and Statistical Analyses}

The goodness of fit of the lactation curve model was evaluated using the mean bias, RMSPE, and concordance correlation coefficient (CCC) statistics as described by Tedeschi (2006). In brief, mean bias is the average of model residuals and provides an estimate of average over- or underprediction, and RMSPE is the average of the squared residuals and is an indicator of predictive model accuracy. The CCC statistic provides a simultaneous evaluation of both the accuracy and the precision of model predictions. Model fit is considered to be improved when the mean bias and RMSPE statistics are minimized and the CCC statistic approaches unity. Model fits were evaluated for the data set as a whole as well as split into pre- and postpeak lactation periods based on the estimated $t_{P}$ parameter for each animal.

Pearson correlation coefficients between lactation curve parameter estimates and estimates of feed efficiency, stratified by period of lactation, were estimated using the CORR procedure of SAS (SAS Institute Inc.). Hypothesis tests were considered statistically significant where $P<0.05$ and tendencies where 0.05 $\leq P<0.15$.

\section{RESULTS AND DISCUSSION}

\section{Residual Energy Intake and Body Reserves}

The updated regression equation (with associated SE in parentheses) for the prediction of REI was found to be

$$
\begin{gathered}
\mathrm{NEI}_{i j}=12.1(1.42)+\mathrm{DIM}_{j}+0.284(0.0143) \times \text { NELact }_{i} \\
+1.84(0.225) \times \mathrm{NEMaint}_{i}-0.00335(0.000780) \\
\times \mathrm{RE}_{i}+0.121(0.0290) \times \mathrm{REGain}_{i}-0.243(0.0179) \\
\times \mathrm{RELoss}_{i}+\mathrm{REI}_{i j}
\end{gathered}
$$

where terms are as described previously. When comparing the updated regression equation with that initially published by Seymour et al. (2020), similar estimates were achieved for the intercept (13.9 vs. 12.1) and NELact (0.34 vs. 0.28 ). The NEMaint term can also be expressed relative to metabolic $\mathrm{BW}\left(\mathbf{M B W} ; \mathrm{BW}^{0.75}\right)$, yielding an estimate of average daily maintenance requirements of $0.147 \mathrm{Mcal}$ of $\mathrm{NE}_{\mathrm{L}} / \mathrm{d}$ per kilogram of $\mathrm{MBW}$. This estimate is almost double the value of 0.08 currently used by NRC (2001) and likely reflects the effect of the substantial hypertrophic and hyperplastic growth occurring during early lactation (Baumgard et al., 2017; Seymour et al., 2020) in addition to the effects of genetic selection on increased body and organ size (Moraes et al., 2015).

As defined by NRC (2001), body reserves used to estimate body $\mathrm{RE}$ are composed of both adipose and protein. Bell (1995) estimated that approximately $25 \%$ of total body protein could be considered a labile reserve pool; however, only a small portion of this would be used to support hepatic gluconeogenesis in the first 2 wk of lactation, with the majority of liberated AA used to support milk protein synthesis. As such, adipose tissue can be considered the main component of body reserves affecting voluntary feed intake. As adipose tissue accumulates in the body, production of leptin increases, which serves to decrease voluntary feed intake (Forbes, 2000; Ingvartsen and Andersen, 2000); this is reflected in the negative partial regression coefficient of body RE. When energy is liberated from adipose tissue in the form of nonesterified fatty acids, these are transported to the liver where they are oxidized, also acting to reduce voluntary feed intake (Allen et al., 2009; Drackley, 2016); this phenomenon is captured in the partial regression coefficient of RELoss. The positive partial regression coefficient of REGain can be attributed to the generalized growth of the animals over the experimental period, as previously observed (Seymour et al., 2020). As anabolic processes remove substrates from circulation, voluntary feed intake is stimulated through various signaling mechanisms (Forbes, 2007).

It is important to note that the coefficients of REGain and RELoss should not be misinterpreted as the combined partial efficiencies of tissue accretion or loss. Both protein and lipid turnover represent the net sum of respective synthetic and degradative pathways that 
are occurring simultaneously (Baldwin et al., 1980). Currently, it is thought that the overall rate of turnover of these tissues is controlled predominantly by alterations to the rates of synthesis, whereas the rates of degradation remain relatively constant (McNamara, 1989; Boisclair et al., 1993). Considering this, REGain can be considered the state where the synthetic rates of protein or lipid synthesis overtake degradation, and RELoss can be considered the state where synthesis proceeds slower than degradation. It is likely that the synthesis and degradation of both lipid and protein have individual partial efficiencies that would contribute to more accurate estimates of energy dynamics (Veerkamp et al., 1995). Currently, NRC (2001) uses partial efficiencies per kilogram of body reserves gained or lost, assuming relative proportions of fat and protein based on BCS.

\section{Interpretation of the Dijkstra Lactation Curve Model}

The Dijkstra model assumes a constant rate of milk synthesis per secretory cell; that is,

$$
M=Y N,
$$

where milk yield $(M)$ is the product of the average milk yield per secretory cell $(Y)$ and the secretory cell population ( $N$; Dijkstra et al., 1997). Considering this, the parameter $M_{0}$ is composed of the estimates of both the average milk yield per secretory cell and the initial secretory cell population $N_{0}$, serving as both the intercept for the curve modeling the secretory cell population over time and the scale parameter that adjusts the model output from cell number to milk production. The assumption regarding secretory activity is likely violated during the period before peak lactation (Capuco and Ellis, 2013; Capuco and Choudhary, 2020), and the inability to account for dynamic secretory activity per cell during this period results in potentially nonphysiological estimates for the other parameters in the model (Dijkstra et al., 1997).

Using the equations developed by Dijkstra et al. (1997), the persistency of lactation on a given day can be described relative to the cell population as

$$
M^{\prime}=\frac{\mathrm{d} M}{\mathrm{~d} t}=Y \frac{\mathrm{d} N}{\mathrm{~d} t}=Y(\mu N-\lambda N)=Y N(\mu-\lambda)
$$

where $\mu$ is the specific rate of secretory cell proliferation. In the model, $\mu$ decays exponentially relative to time and the parameter $k_{2}$,

$$
\mu=\mu_{T} \exp \left(-k_{2} t\right)
$$

whereas the rate of apoptosis $(\lambda)$ remains constant. Thus, as lactation progresses, the specific rate of cell proliferation in the model approaches zero. This drives the underlying behavior of the lactation curve model; while $\mu>\lambda$, daily milk yield will increase until it reaches peak lactation where $\mu=\lambda$, such that persistency $M^{\prime}$ $=0$. Following peak lactation, the rate at which daily milk yield declines increases until $\mu$ is effectively 0 .

To illustrate this point, lactation persistency can be expressed as a percentage of milk yield per day; that is,

$$
M \%=\frac{M^{\prime}}{M}=\frac{Y N(\mu-\lambda)}{Y N}=\mu-\lambda,
$$

where $M \%$ is the rate of change in milk yield in percent per day. As lactation progresses and $\mu$ approaches zero, the decline in daily milk yield, expressed as a percentage of daily milk yield, approaches a rate of $-\lambda \%$ per day. This can be confirmed by comparing the predicted lactation $(M)$ and persistency $\left(M^{\prime}\right)$ curves of a given animal. As such, while the parameter $\lambda$ estimates the specific rate of secretory cell apoptosis, it can also be used to estimate the terminal rate of milk yield decline (i.e., the theoretical persistency in late lactation).

Given the interpretation of the model parameters, it is expected that daily milk yield records as close to parturition as possible are necessary for the accurate estimation of $M_{0}$, whereas daily records up to approximately peak lactation are necessary for the accurate estimation of both $\mu_{T}$ and $k_{2}$. It was observed that supplementing monthly test-day records with daily records up to 21 DIM yielded the best model fit (Figure 2), with an RMSPE of $4.36 \mathrm{~kg} / \mathrm{d}$. In contrast, supplementing monthly records with daily records up to 48 DIM (approximately the average days to peak lactation; Table 1) fit the data with an RMSPE of $4.42 \mathrm{~kg} / \mathrm{d}$. Finally, data in late lactation are required for the accurate estimation of $\lambda$, as persistency of lactation approaches the value of $-\lambda$ as lactation progresses. A limitation of this study was the availability of daily records spanning the full lactation of each animal; as such, we cannot conclusively say that daily records are not needed in late lactation. However, the slope between the last 2 monthly test-day records could provide a relatively accurate estimate of $\lambda$, as this should provide a close estimate to the terminal rate of decline in daily milk yield.

To illustrate the changes in model behavior in different scenarios, Figure 3 presents curves parameterized in 4 different ways based on the average daily and monthly milk yield records. When examining the curve parameterized to the average daily milk yield data up to 150 DIM (dotted line), the behavior of the curve up to peak lactation appears suitable. However, the estimate for 


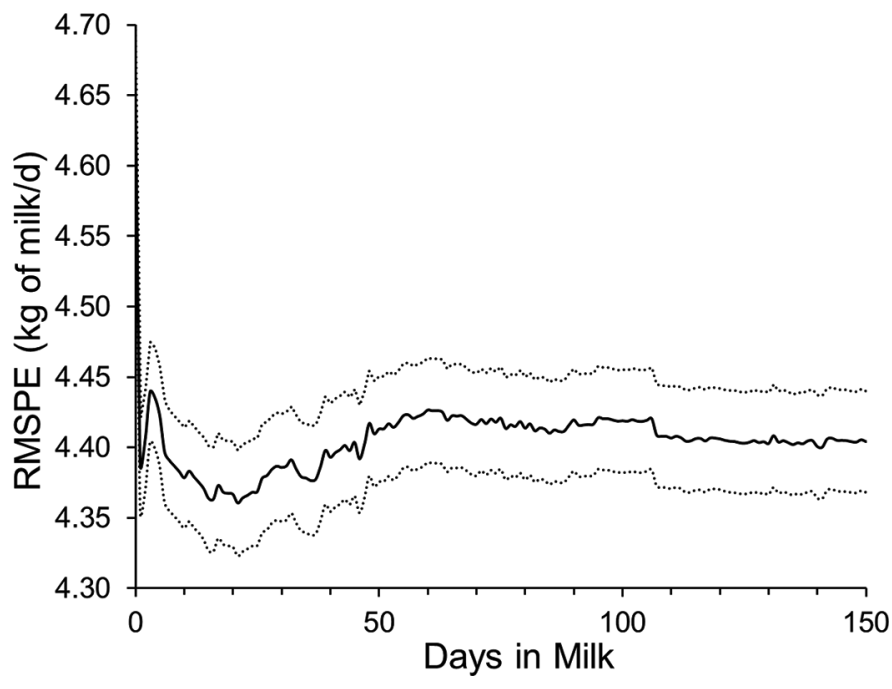

Figure 2. Root mean square prediction error (RMSPE) of lactation curve model based on monthly records with the iterative addition of subsequent daily milk yield records. Solid line: mean RMSPE estimated with bootstrapped case resampling; dotted lines: bounds of $95 \%$ CI.

$\lambda$ is approximately one-third the value of that of the other curves, in addition to being lower than previously reported values (Val-Arreola et al., 2004; Dematawewa et al., 2007; Dijkstra et al., 2010). It is apparent that when using only monthly data spanning the full lactation (dashed line), there is an overestimation of $M_{0}$ and likely an underestimation of both $\mu_{T}$ and $k_{2}$, resulting in a poor fit to the daily records in the first 2 wk of lactation. When comparing the curves parameterized with the addition of daily records up to 21 DIM (Figure 3, solid line) and 48 DIM (dash-dot line) to the monthly records, the estimated values for $M_{0}$ and $\mu_{T}$ are similar to those estimated using only daily records, whereas the estimates of $\lambda$ are more similar to those of the monthly curve; the estimates for $k_{2}$ were intermediate to those of the daily and monthly curves. Interestingly, all curves yielded similar estimates for $M_{P}$. However, estimates for $t_{P}$ were more variable; this value is expected to be

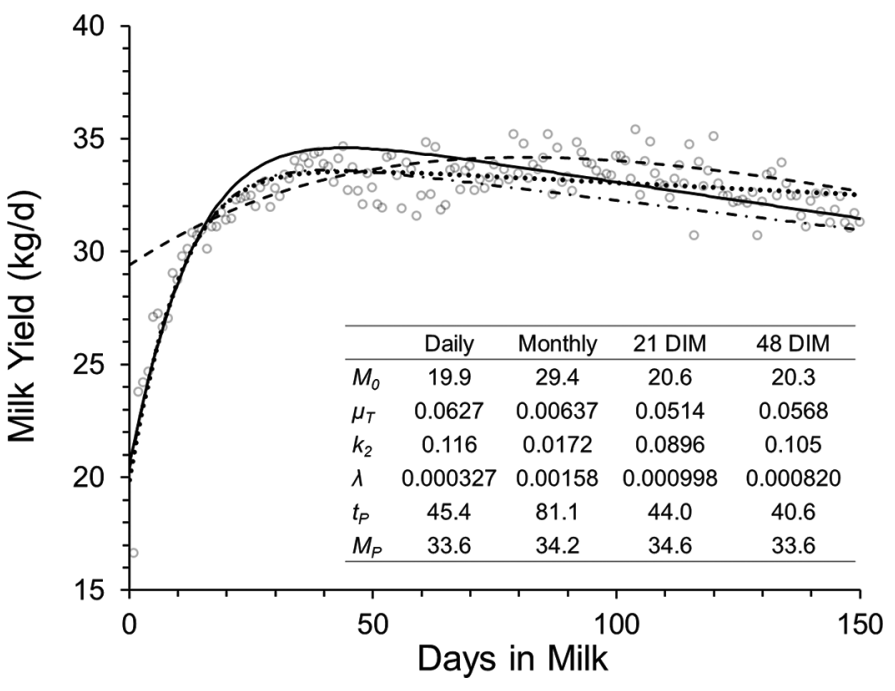

Figure 3. Representative lactation curves parameterized to combinations of average daily and monthly milk yield records collected from primiparous Holstein cattle $(\mathrm{n}=34)$, with parameter estimates superimposed. Dotted line: lactation curve parameterized to exclusively daily records up to 150 DIM (Daily); dashed line: lactation curve parameterized to exclusively monthly records spanning full lactation (Monthly); solid line: lactation curve parameterized to monthly records spanning full lactation supplemented with daily records up to 21 DIM (21 DIM); dash-dot line: lactation curve parameterized to monthly records spanning full lactation supplemented with daily records up to 48 DIM (48 DIM); circles: average of observed daily milk yield. $M_{0}=$ theoretical milk yield at the onset of lactation; $\mu_{T}=$ specific rate of secretory cell proliferation at parturition; $k_{2}=$ rate of decay of cell proliferation; $\lambda=$ specific rate of cell apoptosis; $t_{P}=$ days to peak milk yield; $M_{P}=$ peak milk yield.

more sensitive to changes in $k_{2}$ relative to $\mu_{T}$ or $\lambda$, as $t_{P}$ is inversely proportional to $k_{2}$.

Visually, it can be seen that the 21 DIM curve overpredicts milk yield around peak lactation, whereas the 48 DIM curve underestimates yields after approximately 75 DIM. Overall, these results suggest that the serial addition of daily milk yield records improved model fit such that the behavior around peak lactation was better characterized at the expense of impaired fit later in lactation. In the current data set, the inclusion of daily records up to 21 DIM yielded parameter

Table 1. Distribution of lactation curve parameter estimates generated from records collected from primiparous Holstein heifers $(\mathrm{n}=34)$

\begin{tabular}{lccccc}
\hline Item $^{1}$ & Mean \pm SEM & SD & CV $(\%)$ & Minimum & Maximum \\
\hline$M_{0}(\mathrm{~kg} / \mathrm{d})$ & $17.8 \pm 0.89$ & 5.19 & 29.1 & 5.86 & 25.86 \\
$\mu_{T}\left(\mathrm{~d}^{-1}\right)$ & $0.197 \pm 0.0610$ & 0.356 & 181 & 0.00946 & 1.78 \\
$k_{2}\left(\mathrm{~d}^{-1}\right)$ & $0.192 \pm 0.0410$ & 0.229 & 124 & 0.0175 & 1.16 \\
$\lambda\left(\mathrm{d}^{-1}\right)$ & $0.000941 \pm 0.0001069$ & 0.000623 & 66.2 & 0.000202 & 0.00308 \\
$t_{P}(\mathrm{~d})$ & $47.9 \pm 5.58$ & 32.5 & 68.0 & 6.66 & 172 \\
$M_{P}(\mathrm{~kg} / \mathrm{d})$ & $34.7 \pm 0.84$ & 4.90 & 14.1 & 23.3 & 44.6 \\
\hline
\end{tabular}

${ }^{1} M_{0}=$ theoretical milk yield at the onset of lactation; $\mu_{T}=$ specific rate of secretory cell proliferation at parturition; $k_{2}=$ rate of decay of cell proliferation; $\lambda=$ specific rate of cell apoptosis; $t_{P}=$ days to peak milk yield; $M_{P}=$ peak milk yield. 
estimates that provided the best average fit to the data. As discussed subsequently, the variation in daily milk yield due to the inclusion of data from an automated milking system (AMS) likely influenced estimates of model fit. Evaluating this methodology with a data set containing daily milk yield records spanning the full lactation is warranted to better determine an optimal mix of monthly and daily milk yield records.

\section{Lactation Curve Modeling}

As all feed efficiency measures presented herein are based on the energy content of milk and not solely milk yield, we first attempted to model daily fat- and protein-corrected milk (FPCM) yields such that the aspects of the lactation curves were more closely related to the associated estimates of feed efficiency. However, the changes in milk component concentrations over the course of lactation (i.e., elevated at parturition and declining thereafter) served to offset the lower milk yields in early lactation, resulting in relatively constant daily FPCM yields over the 150-d period of feed efficiency measurements. Due to the relatively small slope of the FPCM curve after peak milk yield, the NLIN procedure of SAS (SAS Institute Inc.) was consistently unable to generate estimates for the parameter $\lambda$ that satisfied the greater-than-zero constraint. This likely reflects the inability of the model to account for the dynamic secretory activity per cell in early lactation, as previously discussed. Considering this, it must be acknowledged that the model parameters do not fully account for changes in the energy content of milk over the course of lactation.

An overview of the lactation curve parameter estimates is provided in Table 1 . The model was unable to fit the data of 1 animal. Additionally, the value of $\lambda$ for 5 animals was estimated to be several orders of magnitude smaller than the remainder of the estimates as well as those previously reported in the literature (Val-Arreola et al., 2004; Dematawewa et al., 2007; Dijkstra et al., 2010); these likely resulted as an attempt to satisfy the greater-than-zero constraints imposed on the model and were treated as erroneous. This resulted in a final subset of 34 animals with feed efficiency data and lactation curve parameters. The estimates for $M_{0}$, $\mu_{T}$, and $k_{2}$ were intermediate to those previously estimated for primiparous cattle (Val-Arreola et al., 2004; Dematawewa et al., 2007; Dijkstra et al., 2010). The average estimate for $\lambda$ was lower than those reported by Val-Arreola et al. (2004) and Dijkstra et al. (2010) but was similar to the estimates for 305-d lactations in primiparous cattle reported by Dematawewa et al. (2007) based on data from 235,241 individual lactations.
When examining the model parameter estimates, a significant amount of variation can be seen. This may be partially attributed to the characteristics of lactation curves in primiparous cattle. Lactation curves of multiparous dairy cattle typically display very pronounced peaks at approximately 45 to 60 DIM, whereas those of primiparous animals often do not have a discernable peak and instead appear to reach a plateau before slowly declining (e.g., Figure 1). This is reflected in the range of estimates for days to peak milk yield $\left(t_{P}\right.$; Table 1), with a minimum time to peak of just under $7 \mathrm{~d}$, whereas the maximum was estimated to be $172 \mathrm{~d}$.

An additional factor of the data set contributing to challenges in model parameterization was the use of daily milk yield records from an AMS. Relative to animals milked in a conventional $2 \times$ daily setting, there is inherently more variation in milking interval both between and within animals in an AMS setting. This introduces challenges in quantifying comparable 24-h milk yields. As an example, an animal could enter the AMS at $0001 \mathrm{~h}$ on $\mathrm{d} 1$. Using our current methodology, the yield in that milking would contribute only to the 24 -h yield on d 1 . However, it follows that the majority of the synthesis of the milk from that time point could be attributed to $\mathrm{d} 0$. Incidences such as this are evident in the data, where animals had days with low 24-h milk yields followed by days with much higher 24-h yields. Currently, there is no quorum on the estimation of 24 -h yields in AMS settings. In the study of Masía et al. (2020), who also used AMS data to model lactation curves, 24-h yields were calculated based on calendar day, which was the method used in the present study. The guidelines provided by the International Committee for Animal Recording (ICAR, 2017) recommend using a moving average, though the methodologies described are more applicable to the estimation of testday yields rather than serial daily milk yields. Of the 6 lactation curves that were removed from subsequent analyses, 3 did not contain any data from the AMS, whereas the remaining 3 contained AMS data for 14, 30 , and $87 \mathrm{~d}$ out of the 150 available. Of the 34 lactation curves retained for analysis, 19 did not contain any AMS data, whereas the remainder contained 6 to 124 d of data from the AMS. This suggests that although the use of AMS data may contribute to the day-to-day variation of milk yield within an animal, it did not affect the ability to generate parameter estimates. However, the variation in daily milk yield likely affected the overall evaluation of model fit (e.g., RMSPE). The development of a more robust method for the calculation of 24-h corrected milk yields in AMS settings is warranted, which would help ensure that lactation data are more comparable with those recorded in settings 
Table 2. Model fit statistics for Dijkstra lactation model in primiparous Holstein heifers $(\mathrm{n}=34)^{1}$

\begin{tabular}{lccc}
\hline Phase & MB $(\mathrm{kg} / \mathrm{d})$ & RMSPE $(\mathrm{kg} / \mathrm{d})$ & $\mathrm{CCC}$ \\
\hline Prepeak & -0.0552 & 4.09 & 0.765 \\
Postpeak & 0.0257 & 4.41 & 0.480 \\
Total & $-5.23 \mathrm{E}-6$ & 4.31 & 0.609 \\
\hline
\end{tabular}

${ }^{1} \mathrm{MB}=$ mean bias; RMSPE $=$ root mean square prediction error; $\mathrm{CCC}$ $=$ concordance correlation coefficient.

with regular milking intervals and support a more reliable evaluation of model fit.

Model fit statistics are presented in Table 2. For the entire 150 DIM period, the model showed effectively no mean bias, with an RMSPE of $4.31 \mathrm{~kg} / \mathrm{d}$ and a CCC of 0.609. When split into pre- and postpeak segments, the model fit was much better in the period before peak lactation relative to the period after peak (Table 2), with a shift from underprediction of $0.0552 \mathrm{~kg} / \mathrm{d}$ in the prepeak phase to overprediction of $0.0257 \mathrm{~kg} / \mathrm{d}$ postpeak. This relationship is similar to that previously discussed when evaluating models fit to the average daily milk yield, where better characterization of the lactation curve around peak lactation was achieved at the expense of poorer fit later in lactation, resulting in a better average fit overall. It is expected that both the high degree of variability in estimated days to peak and the variation in daily milk yield due to AMS milk yield data contributed to model errors.

\section{Prepeak Lactation}

An overview of the feed efficiency estimates for the 34 animals with valid lactation curve parameters is provided in Table 3, and correlations between Dijkstra model parameters and average feed efficiency during the period up to peak lactation are presented in Table
4. Without supporting biological data on mammary secretory cell dynamics, it is difficult to draw meaningful conclusions regarding the correlations related to the parameters $\mu_{T}$ and $k_{2}$. Considering this, emphasis is instead put on the parameters that are estimated using these values, namely $t_{P}$ and $M_{P}$.

The GFE was negatively correlated with $t_{P}(\mathrm{r}=$ $-0.578, P=0.001)$ but positively correlated with $M^{\prime}$ $(\mathrm{r}=0.798, P<0.001)$. A similar relationship can be seen with $\mathrm{NEE}_{\mathrm{F}}$, whereas mean NEBal was positively associated with $t_{P}$ and negatively associated with $M^{\prime}$ (Table 4). Additionally, cumulative NEBal was negatively associated with milk yield at parturition $\left(M_{0}\right.$; $\mathrm{r}=-0.568, P=0.001)$ and peak milk yield $\left(M_{P} ; \mathrm{r}\right.$ $=-0.582, P=0.001)$. The ROFC was also positively associated with $M_{P}(\mathrm{r}=0.667, P<0.001)$. Together, these results suggest that animals that have higher milk yields at parturition and peak milk yield, and that reach peak milk yield earlier and more quickly, may have improved feed efficiency as measured by GFE and ROFC at the expense of increased mobilization of body reserves. Given that these measures of feed efficiency are rudimentary and are both increased in situations of increased milk yield, decreased feed intake, or both, these associations are not surprising. Considering that GFE and ROFC are likely the easiest of the feed efficiency metrics discussed herein to implement in practice, their relationship with increased mobilization of body reserves highlights the need for proper management during the transition period to promote animal health (Drackley, 2001; Cardoso et al., 2013).

Interestingly, $\mathrm{NEE}_{\mathrm{F}}$ was negatively associated with $M_{0}(\mathrm{r}=-0.566, P=0.001)$, which suggested that animals with a lower milk yield at parturition had a greater proportion of available $\mathrm{NE}_{\mathrm{L}}$ derived from body reserves. Given the weak relationship between $M_{0}$ and RELoss ( $\mathrm{r}=0.453, P=0.007)$, it is unlikely that this

Table 3. Distribution of feed efficiency measures over the first 150 DIM in primiparous Holstein heifers $(\mathrm{n}=34)$

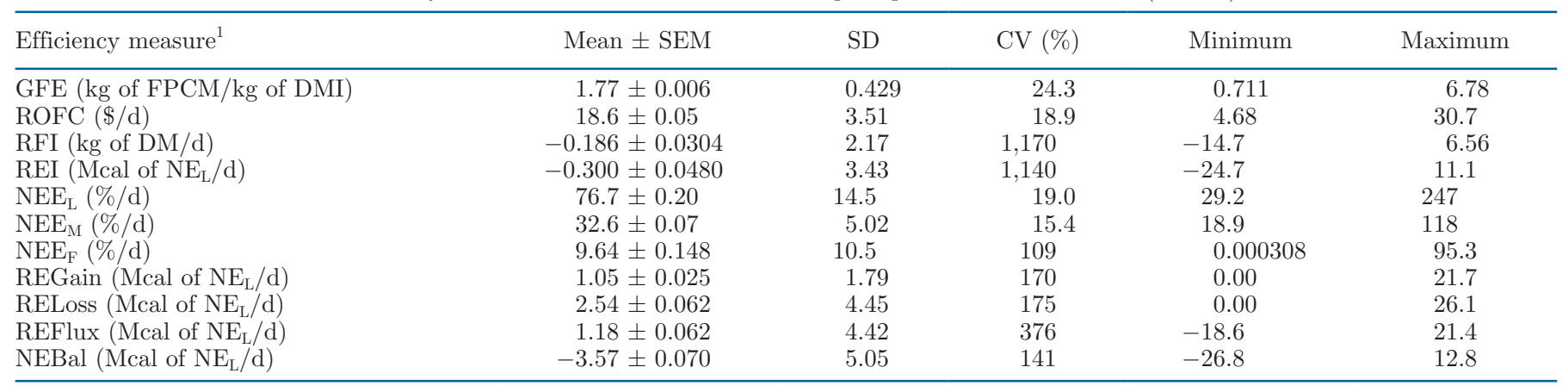

${ }^{1} \mathrm{GFE}=$ gross feed efficiency; FPCM $=$ fat- and protein-corrected milk; ROFC $=$ return over feed costs; RFI $=$ residual feed intake; REI $=$ residual net energy intake; $\mathrm{NEE}_{\mathrm{L}}=$ net energy efficiency of lactation; $\mathrm{NEE}_{\mathrm{M}}=$ net energy efficiency of maintenance; $\mathrm{NEE}_{\mathrm{F}}=$ net energy efficiency of reserve energy flux; REGain = gain in body reserve energy; RELoss = loss in body reserve energy; REFlux = flux of body reserve energy; NEBal = net energy balance. 
Table 4. Correlations between parameter estimates of the Dijkstra lactation curve model and estimates of feed efficiency before peak lactation in primiparous Holstein heifers $(\mathrm{n}=34)^{1}$

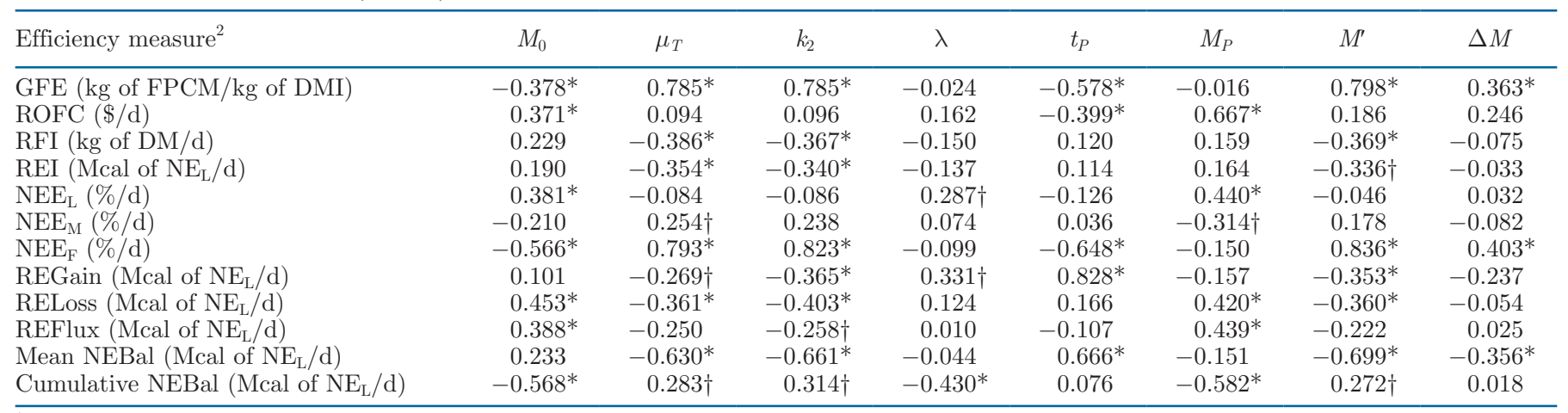

${ }^{1} M_{0}=$ theoretical milk yield at the onset of lactation; $\mu_{T}=$ specific rate of secretory cell proliferation at parturition; $k_{2}=$ rate of decay of cell proliferation; $\lambda=$ specific rate of cell apoptosis; $t_{P}=$ days to peak milk yield; $M_{P}=$ peak milk yield; $M^{\prime}=$ rate of change in daily milk yield; $\Delta M=$ magnitude of change from initial to peak milk yield.

${ }^{2} \mathrm{GFE}=$ gross feed efficiency; FPCM $=$ fat- and protein-corrected milk; ROFC $=$ return over feed costs; RFI $=$ residual feed intake; REI $=$ residual net energy intake; $\mathrm{NEE}_{\mathrm{L}}=$ net energy efficiency of lactation; $\mathrm{NEE}_{\mathrm{M}}=$ net energy efficiency of maintenance; $\mathrm{NEE}_{\mathrm{F}}=$ net energy efficiency of reserve energy flux; REGain = gain in body reserve energy; RELoss = loss in body reserve energy; REFlux = flux of body reserve energy; NEBal = net energy balance.

$* P<0.05 ; \dagger 0.05 \leq P<0.15$.

is the case. The association between $\mathrm{NEE}_{\mathrm{F}}$ and $M_{0}$ potentially reflects smaller animals with lower initial milk yields consuming less feed, resulting in a greater proportion of energy being derived from body reserves. Other metrics of feed efficiency were found to be poorly correlated with aspects of the lactation curve in the period before peak lactation (Table 4).

\section{Postpeak Lactation}

In the postpeak phase of lactation, most measures of feed efficiency displayed weak relationships to parameters describing the lactation curve (Table 5). The GFE, ROFC, and $\mathrm{NEE}_{\mathrm{L}}$ were positively associated with peak milk yield $\left(M_{P} ; \mathrm{r} \geq 0.538, P \leq 0.012\right)$. This is to be expected because animals with a higher peak milk yield generally produce more milk for the remainder of lactation, offsetting the negative components of feed intake in the case of $\mathrm{GFE}$ and $\mathrm{ROFC}$ while requiring a greater proportion of available $\mathrm{NE}_{\mathrm{L}}$ to support lactation in the case of $\mathrm{NEE}_{\mathrm{L}}$. It is important to note that the data set contained information pertaining to feed efficiency only up to 150 DIM. Considering this, in conjunction with the variation in estimates of $t_{P}$, animals had a varying number of observations in the postpeak phase of lactation; indeed, 1 animal was estimated to reach peak lactation at 172 DIM, resulting in no postpeak feed efficiency data. The postpeak phase of lactation for all other animals ranged from 53 to $143 \mathrm{~d}$ in length. Future work using a data set comprising feed efficiency data spanning the full lactation would help to better characterize associations between the lactation curve and feed efficiency after peak lactation.

\section{Feed Efficiency and Persistency of Lactation}

Capuco et al. (2003) postulated that lactation efficiency could be increased by improving persistency after reaching peak milk yield. In the current study, weak associations were observed between the terminal persistency $(\lambda)$ and both cumulative NEBal $(\mathrm{r}=-0.430$, $P=0.011)$ and REGain $(\mathrm{r}=0.331, P=0.056)$ while displaying no apparent associations with any other parameter before or after peak lactation (Tables 4 and 5). The lack of records for the remainder of lactation after peak influenced our ability to detect significant associations, and as such these results should be deemed inconclusive. Feed efficiency data from late in lactation, particularly as daily persistency approaches the value of $-\lambda$, would aid in confirming any potential associations between aspects of feed efficiency and persistency of lactation.

\section{Capital Versus Income Breeders}

The interplay between improved feed efficiency at the expense of increased body reserve mobilization highlights the concept of dairy cattle being capital versus income breeders (Stephens et al., 2009), whereby energy demands can be more or less met by energy stored in body reserves (i.e., capital) versus energy obtained directly from the diet (i.e., income). This also has implications for how feed efficiency is evaluated, as the energy capital that is used to supplement energy income in early lactation was gained before the onset of lactation, during either the growing phase for heifers or the previous lactation for multiparous animals. Consid- 
Table 5. Correlations between parameter estimates of the Dijkstra lactation curve model and estimates of feed efficiency after peak lactation in primiparous Holstein heifers $(\mathrm{n}=33)^{1}$

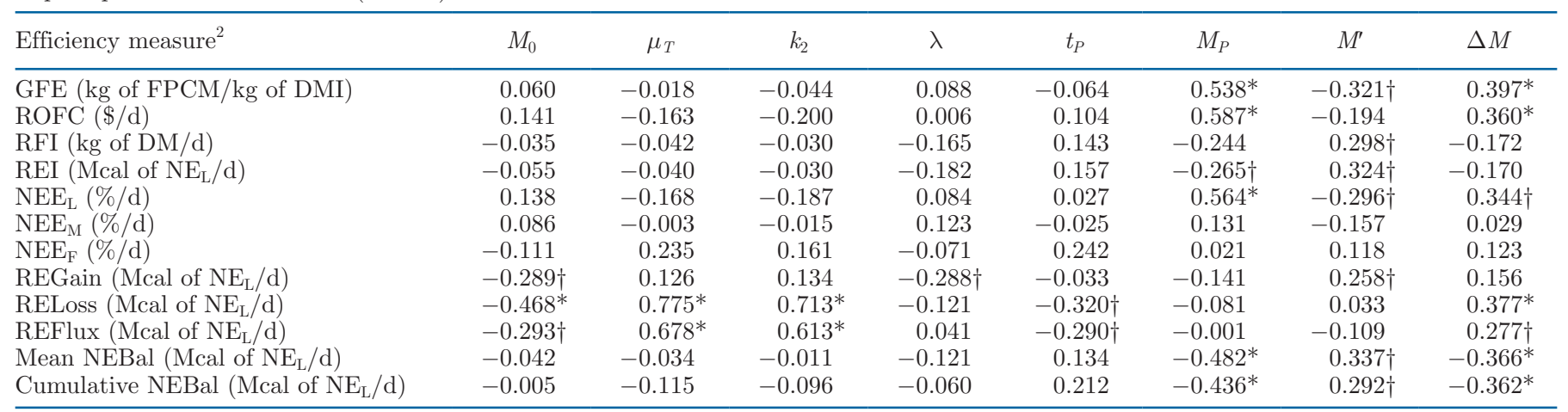

${ }^{1} M_{0}=$ theoretical milk yield at the onset of lactation; $\mu_{T}=$ specific rate of secretory cell proliferation at parturition; $k_{2}=$ rate of decay of cell proliferation; $\lambda=$ specific rate of cell apoptosis; $t_{P}=$ days to peak milk yield; $M_{P}=$ peak milk yield; $M^{\prime}=$ rate of change in daily milk yield; $\Delta M=$ magnitude of change from initial to peak milk yield.

${ }^{2} \mathrm{GFE}=$ gross feed efficiency; FPCM $=$ fat- and protein-corrected milk; ROFC = return over feed costs; RFI = residual feed intake; REI = residual net energy intake; $\mathrm{NEE}_{\mathrm{L}}=$ net energy efficiency of lactation; $\mathrm{NEE}_{\mathrm{M}}=$ net energy efficiency of maintenance; $\mathrm{NEE}_{\mathrm{F}}=$ net energy efficiency of reserve energy flux; RELoss = loss in body reserve energy; REFlux = flux of body reserve energy; Mean NEBal = mean net energy balance over period; Cumulative NEBal = net energy balance summed over period.

${ }^{*} P<0.05 ; \dagger 0.05 \leq P<0.15$.

ering this, evaluating feed efficiency from parturition to the end of lactation inherently implies that dairy cattle are income breeders as it does not capture the period of time during which the animal accretes body reserves, leading to the inflation of traditional feed efficiency estimates in early lactation. Assuming that dairy cattle are in fact capital breeders, it may be more appropriate to begin evaluating feed efficiency from the point at which the animal shifts from the mobilization of body reserves to support the current offspring and begins accumulating body reserves to support the next (Martin and Sauvant, 2010a,b); this appears to occur at approximately 100 to 150 DIM (Phuong et al., 2016; Seymour et al., 2020). As this would coincide with pregnancy testing typical to North American production systems (Stangaferro et al., 2018), a more practical timeframe for the evaluation of feed efficiency in dairy cattle could be from confirmation of pregnancy to the end of the lactation resulting from the associated conceptus.

\section{CONCLUSIONS}

Residual $\mathrm{NE}_{\mathrm{L}}$ intake predictions were updated to incorporate estimates of body $\mathrm{RE}$, with partial regression coefficients in agreement with the underlying biological processes. When characterizing the lactation curves of primiparous cattle using a mathematical model, model fit over the first 150 DIM was improved by supplying a combination of daily records up to 21 DIM and monthly milk reporting records spanning the remainder of lactation. However, variation in daily milk yield due to the inclusion of data from an AMS likely influenced estimates of model fit. In the period of lactation up to peak milk yield, improved feed efficiency was generally associated with greater increases in daily milk yield over shorter periods of time at the expense of increased mobilization of body reserves to support milk production. From peak lactation to 150 DIM, GFE, ROFC, and $\mathrm{NEE}_{\mathrm{L}}$ were positively associated with peak milk yield. No associations were observed between improved persistency of lactation and measures of feed efficiency over the first 150 DIM. Finally, the time frame over which feed efficiency is evaluated could be improved to account for cattle being capital versus income breeders to yield better estimates of true feed efficiency in lactating dairy cattle.

\section{ACKNOWLEDGMENTS}

The authors thank Nicolas Friggens (INRA, AgroParisTech, Paris, France) and Jean-Baptiste Daniel (Trouw Nutrition, Amersfoort, the Netherlands) for their stimulating input regarding the analysis and interpretation of the data as well as the staff at the Ontario Dairy Research Centre (Elora, ON, Canada) for their continued efforts with data collection. We gratefully acknowledge funding by the Efficient Dairy Genome Project, funded by Genome Canada (Ottawa, ON, Canada), Genome Alberta (Calgary, AB, Canada), Ontario Genomics (Toronto, ON, Canada), Alberta Ministry of Agriculture (Edmonton, AB, Canada), Ontario Ministry of Research and Innovation (Toronto, ON, Canada), Ontario Ministry of Agriculture, Food and Rural Affairs (Guelph, ON, Canada), Canadian 
Dairy Network (Guelph, ON, Canada), GrowSafe Systems (Airdrie, AB, Canada), Alberta Milk (Edmonton, AB, Canada), Victoria Agriculture (Australia), Scotland's Rural College (Edinburgh, UK), USDA Agricultural Research Service (Washington, DC), Qualitas AG (Zug, Switzerland), and Aarhus University (Aarhus, Denmark). The authors have not stated any conflicts of interest.

\section{REFERENCES}

Allen, M. S., B. J. Bradford, and M. Oba. 2009. Board invited review: The hepatic oxidation theory of the control of feed intake and its application to ruminants. J. Anim. Sci. 87:3317-3334. https://doi .org/10.2527/jas.2009-1779.

Baldwin, R. L., N. E. Smith, J. Taylor, and M. Sharp. 1980. Manipulating metabolic parameters to improve growth rate and milk secretion. J. Anim. Sci. 51:1416-1428. https://doi.org/10.2527/ jas1981.5161416x.

Baumgard, L. H., R. J. Collier, and D. E. Bauman. 2017. A 100-year review: Regulation of nutrient partitioning to support lactation. J. Dairy Sci. 100:10353-10366. https://doi.org/10.3168/jds.2017 -13242 .

Bell, A. W. 1995. Regulation of organic nutrient metabolism during transition from late pregnancy to early lactation. J. Anim. Sci. 73:2804-2819. https://doi.org/10.2527/1995.7392804x.

Boisclair, Y. R., A. W. Bell, F. R. Dunshea, M. Harkins, and D. E. Bauman. 1993. Evaluation of the arteriovenous difference technique to simultaneously estimate protein synthesis and degradation in the hindlimb of fed and chronically underfed steers. J. Nutr. 123:1076-1088. https://doi.org/10.1093/jn/123.6.1076.

Brito, L. F., H. R. Oliveira, K. Houlahan, P. A. S. Fonseca, S. Lam, A. M. Butty, D. J. Seymour, G. Vargas, T. C. S. Chud, F. F. Silva, C. F. Baes, A. Cánovas, F. Miglior, and F. S. Schenkel. 2020. Genetic mechanisms underlying feed utilization and implementation of genomic selection for improved feed efficiency in dairy cattle. Can. J. Anim. Sci. 100:587-604. https://doi.org/10.1139/cjas-2019-0193.

Capuco, A. V., and R. K. Choudhary. 2020. Symposium review: Determinants of milk production: Understanding population dynamics in the bovine mammary epithelium. J. Dairy Sci. 103:2928-2940. https://doi.org/10.3168/jds.2019-17241.

Capuco, A. V., and S. E. Ellis. 2013. Comparative aspects of mammary gland development and homeostasis. Annu. Rev. Anim. Biosci. 1:179-202. https://doi.org/10.1146/annurev-animal-031412 -103632 .

Capuco, A. V., S. E. Ellis, S. A. Hale, E. Long, R. A. Erdman, X. Zhao, and M. J. Paape. 2003. Lactation persistency: Insights from mammary cell proliferation studies. J. Anim. Sci. 81(Suppl. 3):1831. https://doi.org/10.2527/2003.81suppl_318x.

Cardoso, F. C., S. J. LeBlanc, M. R. Murphy, and J. K. Drackley. 2013. Prepartum nutritional strategy affects reproductive performance in dairy cows. J. Dairy Sci. 96:5859-5871. https://doi.org/ 10.3168/jds.2013-6759.

Cassell, D. L. 2007. Don't be loopy: Re-sampling and simulation the SAS way. Paper no. 183-2007 in SAS Global Forum 2007. SAS Institute Inc.

Cook, R. D., and C.-L. Tsai. 1985. Residuals in nonlinear regression. Biometrika 72:23-29. https://doi.org/10.1093/biomet/72.1.23.

Dematawewa, C. M. B., R. E. Pearson, and P. M. VanRaden. 2007. Modeling extended lactations of Holsteins. J. Dairy Sci. 90:39243936. https://doi.org/10.3168/jds.2006-790.

Dijkstra, J., J. France, M. S. Dhanoa, J. A. Maas, M. D. Hanigan, A. J. Rook, and D. E. Beever. 1997. A model to describe growth patterns of the mammary gland during pregnancy and lactation. J. Dairy Sci. 80:2340-2354. https://doi.org/10.3168/jds.S0022 $-0302(97) 76185-X$.

Dijkstra, J., S. Lopez, A. Bannink, M. S. Dhanoa, E. Kebreab, N. E. Odongo, M. H. Fathi Nasri, U. K. Behera, D. Hernandez-Ferrer, and J. France. 2010. Evaluation of a mechanistic lactation model using cow, goat and sheep data. J. Agric. Sci. 148:249-262. https: //doi.org/10.1017/S0021859609990578.

Drackley, J. K. 2001. Management of transition cows: Integrating nutrition and stress physiology. Pages 148-159 in Proc. Cornell Nutrition Conference for Feed Manufacturers.

Drackley, J. K. 2016. The importance of BCS management to cow welfare, performance and fertility. Pages 195-206 in Proc. Western Canadian Dairy Seminar, Red Deer, AB.

Fischer, A., R. Delagarde, and P. Faverdin. 2018. Identification of biological traits associated with differences in residual energy intake among lactating Holstein cows. J. Dairy Sci. 101:4193-4211. https: //doi.org/10.3168/jds.2017-12636.

Forbes, J. M. 2000. Physiological and metabolic aspects of feed intake control. Pages 319-333 in Farm Animal Metabolism and Nutrition. J. P. F. D'Mello, ed. CABI.

Forbes, J. M. 2007. A personal view of how ruminant animals control their intake and choice of food: Minimal total discomfort. Nutr. Res. Rev. 20:132-146. https://doi.org/10.1017/S0954422407797834.

Grossman, M., S. M. Hartz, and W. J. Koops. 1999. Persistency of lactation yield: A novel approach. J. Dairy Sci. 82:2192-2197. https: //doi.org/10.3168/jds.S0022-0302(99)75464-0.

Grossman, M., and W. J. Koops. 1988. Multiphasic analysis of lactation curves in dairy cattle. J. Dairy Sci. 71:1598-1608. https://doi .org/10.3168/jds.S0022-0302(88)79723-4.

Grossman, M., and W. J. Koops. 2003. Modeling extended lactation curves of dairy cattle: A biological basis for the multiphasic approach. J. Dairy Sci. 86:988-998. https://doi.org/10.3168/jds .S0022-0302(03)73682-0.

ICAR (International Committee for Animal Recording). 2017. Procedure 1 of Section 2 of ICAR Guidelines - Computing 24-hour Yields. Accessed Apr. 14, 2021. https://www.icar.org/Guidelines/ 02-Procedure-1-Computing-24-Hour-Yield.pdf.

Ingvartsen, K. L., and J. B. Andersen. 2000. Integration of metabolism and intake regulation: A review focusing on periparturient animals. J. Dairy Sci. 83:1573-1597. https://doi.org/10.3168/jds .S0022-0302(00)75029-6.

Koch, R. M., L. A. Swiger, D. Chambers, and K. E. Gregory. 1963. Efficiency of feed use in beef cattle. J. Anim. Sci. 22:486-494. https: //doi.org/10.2527/jas1963.222486x.

Martin, O., and D. Sauvant. 2010a. A teleonomic model describing performance (body, milk and intake) during growth and over repeated reproductive cycles throughout the lifespan of dairy cattle. 1. Trajectories of life function priorities and genetic scaling. Animal 4:2030-2047. https://doi.org/10.1017/S1751731110001357.

Martin, O., and D. Sauvant. 2010b. A teleonomic model describing performance (body, milk and intake) during growth and over repeated reproductive cycles throughout the lifespan of dairy cattle. 2. Voluntary intake and energy partitioning. Animal 4:2048-2056. https://doi.org/10.1017/S1751731110001369.

Masía, F. M., N. A. Lyons, M. Piccardi, M. Balzarini, R. C. Hovey, and S. C. Garcia. 2020. Modeling variability of the lactation curves of cows in automated milking systems. J. Dairy Sci. 103:81898196. https://doi.org/10.3168/jds.2019-17962.

McNamara, J. P. 1989. Regulation of bovine adipose tissue metabolism during lactation. 5. Relationships of lipid synthesis and lipolysis with energy intake and utilization. J. Dairy Sci. 72:407-418. https://doi.org/10.3168/jds.S0022-0302(89)79122-0.

Miglior, F., A. Fleming, F. Malchiodi, L. F. Brito, P. Martin, and C. F. Baes. 2017. A 100-year review: Identification and genetic selection of economically important traits in dairy cattle. J. Dairy Sci. 100:10251-10271. https://doi.org/10.3168/jds.2017-12968.

Moraes, L. E., E. Kebreab, A. B. Strathe, J. Dijkstra, J. France, D. P. Casper, and J. G. Fadel. 2015. Multivariate and univariate analysis of energy balance data from lactating dairy cows. J. Dairy Sci. 98:4012-4029. https://doi.org/10.3168/jds.2014-8995.

Morgavi, D. P., E. Forano, C. Martin, and C. J. Newbold. 2010. Microbial ecosystem and methanogenesis in ruminants. Animal 4:10241036. https://doi.org/10.1017/S1751731110000546.

NRC. 2001. Nutrient Requirements of Dairy Cattle.7th rev. ed. Natl. Acad. Sci. 
Phuong, H. N., P. Blavy, O. Martin, P. Schmidely, and N. C. Friggens. 2016. Modelling impacts of performance on the probability of reproducing, and thereby on productive lifespan, allow prediction of lifetime efficiency in dairy cows. Animal 10:106-116. https://doi .org/10.1017/S1751731115001718

Pollott, G. E. 2000. A biological approach to lactation curve analysis for milk yield. J. Dairy Sci. 83:2448-2458. https://doi.org/10 .3168/jds.S0022-0302(00)75136-8.

Pot, L. J. 2020. Modelling and forecasting extended lactations in Holstein-Friesian dairy cattle. MSc Thesis. Department of Animal Biosciences, University of Guelph, Guelph, ON, Canada.

Rook, A. J., J. France, and M. S. Dhanoa. 2009. On the mathematical description of lactation curves. J. Agric. Sci. 121:97-102. https:// doi.org/10.1017/S002185960007684X.

Seymour, D. J., A. Cánovas, C. F. Baes, T. C. S. Chud, V. R. Osborne, J. P. Cant, L. F. Brito, B. Gredler-Grandl, R. Finocchiaro, R. F. Veerkamp, Y. de Haas, and F. Miglior. 2019. Invited review: Determination of large-scale individual dry matter intake phenotypes in dairy cattle. J. Dairy Sci. 102:7655-7663. https://doi.org/ $10.3168 /$ jds.2019-16454.

Seymour, D. J., A. Canovas, T. C. S. Chud, J. P. Cant, V. R. Osborne, C. F. Baes, F. S. Schenkel, and F. Miglior. 2020. The dynamic behavior of feed efficiency in primiparous dairy cattle. J. Dairy Sci. 103:1528-1540. https://doi.org/10.3168/jds.2019-17414.

Stangaferro, M. L., R. Wijma, M. Masello, M. J. Thomas, and J. O. Giordano. 2018. Extending the duration of the voluntary waiting period from 60 to 88 days in cows that received timed artificial insemination after the Double-Ovsynch protocol affected the reproductive performance, herd exit dynamics, and lactation performance of dairy cows. J. Dairy Sci. 101:717-735. https://doi.org/10 $.3168 /$ jds.2017-13046.

Stephens, P. A., I. L. Boyd, J. M. McNamara, and A. I. Houston. 2009. Capital breeding and income breeding: Their meaning, measurement, and worth. Ecology 90:2057-2067. https://doi.org/10.1890/ 08-1369.1.
Tedeschi, L. O. 2006. Assessment of the adequacy of mathematical models. Agric. Syst. 89:225-247. https://doi.org/10.1016/j.agsy .2005.11.004.

Val-Arreola, D., E. Kebreab, J. Dijkstra, and J. France. 2004. Study of the lactation curve in dairy cattle on farms in central Mexico. J. Dairy Sci. 87:3789-3799. https://doi.org/10.3168/jds.S0022 -0302(04)73518-3.

VandeHaar, M. J., L. E. Armentano, K. Weigel, D. M. Spurlock, R. J. Tempelman, and R. Veerkamp. 2016. Harnessing the genetics of the modern dairy cow to continue improvements in feed efficiency. J. Dairy Sci. 99:4941-4954. https://doi.org/10.3168/jds .2015-10352.

Veerkamp, R. F., G. C. Emmans, A. R. Cromie, and G. Simm. 1995. Variance components for residual feed intake in dairy cows. Livest. Prod. Sci. 41:111-120. https://doi.org/10.1016/0301 -6226(94)00056-D.

Wilmink, J. B. M. 1987. Adjustment of test-day milk, fat and protein yield for age, season and stage of lactation. Livest. Prod. Sci. 16:335-348. https://doi.org/10.1016/0301-6226(87)90003-0.

Wood, P. D. P. 1967. Algebraic model of the lactation curve in cattle. Nature 216:164-165. https://doi.org/10.1038/216164a0.

\section{ORCIDS}

D. J. Seymour @ https://orcid.org/0000-0001-6208-8720

A. Cánovas @ https://orcid.org/0000-0002-0036-0757

T. C. S. Chud () https://orcid.org/0000-0001-7559-1165

J. P. Cant ๑ https://orcid.org/0000-0003-2021-1764

V. R. Osborne (ㄱ https://orcid.org/0000-0002-8959-8760

C. F. Baes ๑ https://orcid.org/0000-0001-6614-8890

F. S. Schenkel ๑ https://orcid.org/0000-0001-8700-0633

F. Miglior ๑ https://orcid.org/0000-0003-2345-8842 